\title{
Predictors of acute cardiovascular events following acute exacerbation period for patients with COPD: a nested case-control study
}

Wei-ping $\mathrm{Hu}^{1 \dagger}$, Tsokyi Lhamo ${ }^{1,2 \dagger}{ }^{\text {, Feng-ying Zhang }}{ }^{3 \dagger}$, Jing-qing Hang ${ }^{3}$, Yi-hui Zuo ${ }^{1}$, Jian-lan Hua ${ }^{1}$, Shan-qun Li ${ }^{\text {* }}$ and Jing Zhang ${ }^{1 *} \mathbb{D}$

\begin{abstract}
Background: It has been noted that there is an increase in the incidence of acute cardiovascular events (CVEs) in patients with chronic obstructive pulmonary disease (COPD) during an acute exacerbation (AE), thereby causing increased inpatient mortality. Thus, we have tried to identify predictors of acute CVEs in patients with AECOPD via a nested case-control study.
\end{abstract}

Methods: A total of 496 cases hospitalized for AECOPD were included in this study, and followed-up for up to 6 months after discharge. Acute CVEs in the AE period were defined as a new or worsening acute coronary syndrome (ACS), arrhythmia, or left ventricular disfunction (LVD). Predictors of CVEs were selected from several variables, including baseline characteristics and treatments in the stable period as well as symptoms, laboratory tests, complications and treatments in the AE period.

Results: Thirty cases (6.05\%) had acute CVEs, namely 2 had ACS, 13 had LVD and 19 experienced some form of arrhythmia. Four deaths were observed in the CVE group, with significantly increased death risk compared with the non-CVE group $(P=0.001, O R=5.81)$. Moreover, patients who had CVEs were more prone to have re-exacerbation within 3 months. Multivariate analysis showed that previous LVD history $(P=0.004, \mathrm{OR}=5.06), 20 \%$ increase in heart rate (HR) $(P=0.003, \mathrm{OR}=10.19)$, electrolyte disturbance $(P=0.01, \mathrm{OR}=4.24)$ and diuretics $(P=0.002, \mathrm{OR}=6.37)$ were independent predictors of CVEs. In addition, usage of theophylline, fluoroquinolone and inhaled beta agonists in the AE period were not statistically associated with acute CVEs.

Conclusions: Our preliminary study indicates that patients hospitalized for AECOPD with previous LVD history or increased HR need close observation and diuretics should be cautiously used with regular electrolyte monitoring. These findings need to be confirmed in a large cohort.

Keywords: Acute exacerbation of chronic obstructive pulmonary disease, Acute cardiovascular events, Heart rate, Electrolyte disturbance, Diuretics

*Correspondence: li.shanqun@zs-hospital.sh.cn; huxizhangjing@foxmail.com tWei-ping Hu, Tsokyi Lhamo, and Feng-ying Zhang have contributed equally to the paper

${ }^{1}$ Department of Pulmonary and Critical Care Medicine, Zhongshan Hospital, Shanghai Medical College, Fudan University, Shanghai 200032, China

Full list of author information is available at the end of the article

\section{Introduction}

Chronic obstructive pulmonary disease (COPD) is a chronic lung disease characterized by irreversible airflow limitation and progressive decline of lung function, and it is the third leading cause of death in the world $[1,2]$. Several cohort studies reported that cardiovascular disease (CVD) is one of the top three leading causes of death 
in patients with COPD, following respiratory infections and respiratory failure [3-5]. Moreover, previous history of CVD can additionally increase risks of death in elderly COPD patients with pneumonia [6].

Patients with COPD tend to have concurrent CVDs with a prevalence of $28-70 \%$ [7]. Hyperlipidemia (45\%) and hypertension (43\%) have been found to be the most common cardiovascular risk factors [8]. Increased risks of acute cardiovascular events (CVEs) namely acute coronary syndrome (ACS) [9], arrhythmias [7] and sudden cardiac death [10] have also been reported in the patients with COPD. A large cohort study demonstrated that the prevalence of heart failure among patients with COPD is significantly increased, leading to a higher allcause mortality [11]. During a period of acute exacerbation (AE), aggravated hypoxia and systemic inflammation are precipitating factors for acute CVEs, especially in the high-risk population [10, 12, 13]. Therefore, clinicians should remain vigilant for early acute CVEs following AECOPD and identify risk factors, especially the use of potentially-inappropriate medication. However, knowledge of risk factors of CVEs in patients with AECOPD is still incomplete.

Traditional risk factors of CVDs include previous history, hypertension, diabetes, hyperlipidemia and hyperuricemia. In addition, serious side effects of certain drugs might be the chief culprits of some CVE cases. A case-control study reported that theophylline could increase the risk of arrhythmias and acute heart failure by $80 \%$ [14]. Moreover, a meta-analysis showed that fluoroquinolones increased the risk of arrhythmias and cardiovascular death by $80 \%$ and $71 \%$ [15]. The relationship between inhaled beta-receptor agonists (bronchodilators) and CVDs is still highly debated, for beta-receptor antagonist is well-known therapy of cardiac remodeling and heart failure [14]. In the patients with COPD, initiation of inhaled bronchodilators has been related to shortterm elevated risks of severe CVEs [16], and adding a second bronchodilator to the previous monotherapy also slightly increased the risk of heart failure after a one year period [17]. On the other hand, dual bronchodilators (beta-receptor agonists and muscarinic receptor antagonist) have been shown to improve left ventricular filling by reducing lung hyperinflation [18].

Herein, we performed a nested case-control study in a prospective COPD cohort in Shanghai, with the aim of screening the predictive factors of acute CVEs following the onset of AECOPD.

\section{Method}

\section{Patient recruitment and data collection}

We performed a nested case-control study within a prospective cohort. Between January 2015 and July
2017, we recruited patients hospitalized for AECOPD in the Department of Pulmonary Medicine of Shanghai Zhongshan Hospital and Shanghai Putuo District People's Hospital into our prospective cohort.

At the time of admission, patients with a clearly recorded COPD history were interviewed by two separate pulmonologists, to evaluate whether their deteriorated respiratory symptoms were categorized as AECOPD. Exclusion criteria were exacerbations induced by other respiratory diseases, including asthma, bronchiectasis, congestive heart failure, pulmonary embolism, pleuritis, restrictive lung disease and pneumothorax.

Baseline information and conditions during the stable period were recorded at admission; these consisted of demographic characteristics, COPD-associated evaluation (risk factors, lung function, assessment scales and number of previous AE), COPD-associated treatments during the stable period (inhaled agents, oral drugs, assistive breathing and vaccination) and comorbidities (common CVDs, other respiratory diseases and other common diseases). Modified Medical Research Council (mMRC) dyspnea scale [19] and COPD assessment test (CAT) [20] were used to stratify the severity of dyspnea and measure COPD's adverse effects on daily life.

Individualized treatment for each patient in the hospitalization period was carried out according to personal conditions and documents of Global Strategy for Prevention, Diagnosis and Management of COPD (GOLD). Detailed examination and therapeutics in the AE period were recorded, including new or worsening manifestations, vital signs at admission, laboratory tests (blood routine examination, blood biochemistry, coagulation tests, arterial blood gas analysis, etc.), sputum culture, computed tomography, assistive breathing and drug usage (antibiotics, inhaled bronchodilators, inhaled or systemic steroids and others). In addition, we also collected information about emerging or worsened complications (pneumonia, PE, pneumothorax, acute coronary syndrome [ACS], arrhythmia, left ventricular dysfunction [LVD] and others).

At the timepoint of 1, 3 and 6 month after discharge, patients were followed up either by outpatient department visits or by telephone, to prospectively collect information about any recurrent acute exacerbation (re$\mathrm{AE})$ and survival.

Electrolyte disturbance was defined as abnormal electrolyte (including sodium, potassium, calcium, calcium, phosphorus and magnesium) value(s) which were not within the normal range during the blood tests carried out on admission. Diuretics used included torasemide, spironolactone and furosemide. We also noted the category and doses of diuretics prescribed as well as their 
initiation dates. Methylxanthines used included aminophylline, doxophylline and diprophylline.

\section{Outcome}

Primary outcome was any CVEs, including emerging or worsening ACS, LVD and arrhythmia occurring during the AE period. The clinical notes of cases with CVE were retrieved and carefully reviewed to determine the chronological sequence of the use of diuretics, appearance of electrolyte disturbance and CVEs. Secondary outcomes were defined as days of stay in hospital, hospitalized death, death within 1, 3 and 6 months, and recurrent $\mathrm{AE}$ within 1,3 and 6 months. Re-AE was defined as the new worsening of respiratory symptoms lasting for over 2 days, which required additional medical intervention. [2]

\section{Statistical analysis}

Categorical variables were presented as numbers (\%) and compared by Chi-square test or Fisher's exact test for univariate analysis. We analyzed the normality of continuous variables by Shapiro-Wilk normality test, and normal distribution was not universally noted. Thus, continuous variables were described by median (interquartile range [IQR]) and compared by Mann-Whitney U test for univariate analysis. Odds ratio (OR) and corresponding confidence intervals of $95 \%(95 \% \mathrm{CI})$ were used to estimate the association of variables and outcomes. In the multivariable analysis, binary logistic regression model with method of Backward LR was used to identify the independent predictive factors of acute CVEs in AECOPD patients. Variables with $P<0.001$ in the univariate analysis were included into the multivariable analysis.

From the conservative point of view, we managed missing data with the following procedure: firstly, patients with many missing variables were excluded; secondly, variables with missing number $\geq 5 \%$ were removed; thirdly, variables with missing number $<5 \%$ were supplemented with the negative value. Statistical analysis was performed using IBM SPSS statistics 23 (SPSS Inc, Chicago, IL), and statistical graph was generated with GraphPad Prism 6 (GraphPad Software, CA, USA). The statistical significance level was set as a two-tailed $P<0.05$.

\section{Result}

\section{Baseline characteristics}

Between January, 2015 and July, 2017, 514 AECOPD cases were collected in the two hospitals. After excluding those without any record of acute CVEs during hospitalization, we included 496 cases into analysis. (Fig. 1) A total of 30 cases $(6.05 \%)$ had concomitant acute CVEs

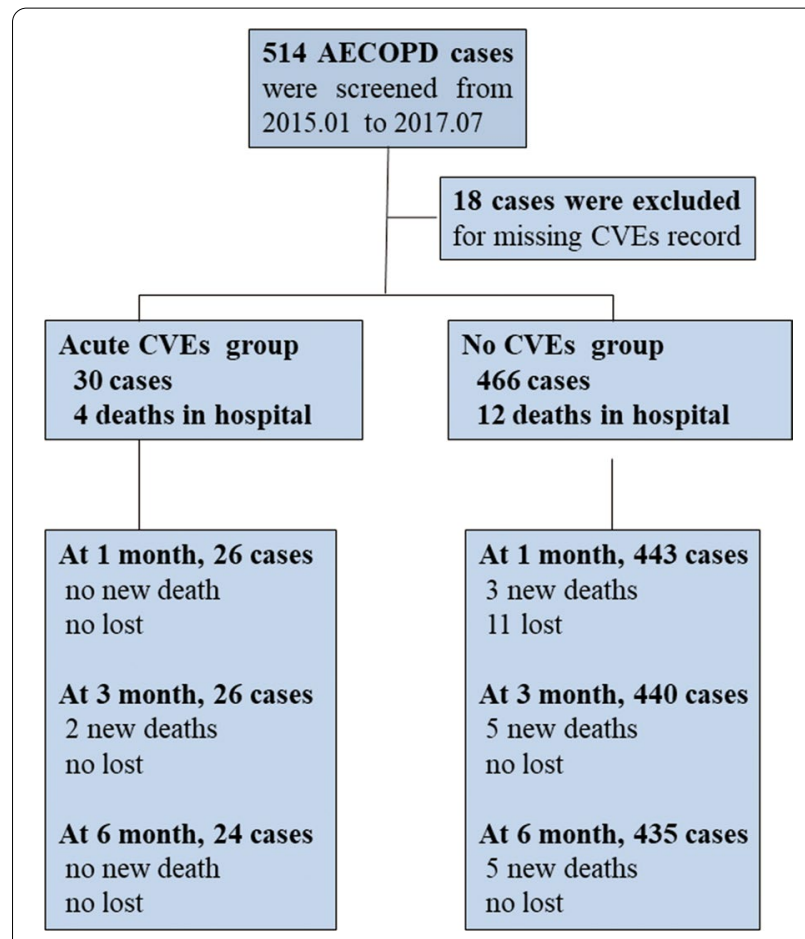

Fig. 1 Flow chart of the study. AECOPD, acute exacerbation of chronic obstructive pulmonary disease; CVEs, cardiovascular events

(ACS, $\mathrm{n}=2$; arrhythmia, $\mathrm{n}=19$; LVD, $\mathrm{n}=13$ ), and 4 cases died in hospital. At 1 month after discharge, 11 patients were lost to follow up.

As shown in Table 1, patients from the acute CVEs group were older than those from the non-CVEs group $(P=0.027)$. Interestingly, females were more susceptible to have acute CVEs during the AECOPD period $(P=0.037, \quad \mathrm{OR}=2.35,95 \% \mathrm{CI}=1.03-5.33)$. As for severity of COPD, two group did not significantly differ in the grading by spirometric values, symptom scores and number of previous 1-year AE.

The presence of other coexisting respiratory diseases were not associated with acute CVEs. On the other hand, prior cardiovascular diseases were strong predictors of acute CVEs in AECOPD: coronary heart disease $(P=0.016, \quad \mathrm{OR}=2.82, \quad 95 \% \quad \mathrm{CI}=1.18-6.75)$ and left heart insufficiency $(P<0.001, \mathrm{OR}=6.42$, $95 \% \mathrm{CI}=2.50-16.48)$. When defined as total cholesterol $>5.2 \mathrm{mmol} / \mathrm{l}$, hyperlipidemia was not associated with increased risk of acute CVEs. Regular usage of inhaled agents for treating COPD in the stable period was a protective factor, especially when inhaled corticosteroid (ICS) and long-acting beta agonist (LABA) combination was used $(P=0.027, \quad \mathrm{OR}=0.34,95 \%$ $\mathrm{CI}=0.12-0.92)$. 
Table 1 Baseline characteristics and cardiovascular risk factors of study population

\begin{tabular}{|c|c|c|c|c|}
\hline Category & Measurements & Acute CVEs group $(n=30)$ & No CVEs group $(n=466)$ & $P$ value \\
\hline \multirow[t]{5}{*}{ Basic information } & Age (year) & $82(77-84)$ & $78(68-84)$ & 0.025 \\
\hline & Male & $21(70.0 \%)$ & $394(84.5 \%)$ & 0.037 \\
\hline & BMI & $22.8(20.0-24.2)(n=15)$ & $21.7(20.2-25.4)(n=314)$ & NS \\
\hline & Smoking history (yes or no) & $21(70.0 \%)$ & $378(81.1 \%)$ & NS \\
\hline & Smoking history (pack*year) & $43.5(31.8-57.5)(n=12)$ & $46.0(34.3-60.0)(n=192)$ & NS \\
\hline \multirow[t]{7}{*}{ COPD severity } & $\mathrm{FEV}_{1}(\%$ predicted $)$ & $40.2(29.3-53.7)(n=15)$ & $37.2(28.4-49.0)(n=300)$ & NS \\
\hline & GOLD grade I & $0(0 \%)$ & $1(0.3 \%)$ & NS \\
\hline & GOLD grade $\|$ & $2(13.3 \%)$ & $66(22.0 \%)$ & \\
\hline & GOLD grade III & $6(40.0 \%)$ & $144(48.0 \%)$ & \\
\hline & GOLD grade IV & $5(33.3 \%)$ & $89(29.7 \%)$ & \\
\hline & mMRC score & $3(2-3)(n=17)$ & $3(2-3)(n=324)$ & NS \\
\hline & CAT score & $23.5(12.3-26.8)(n=16)$ & $22.0(15.0-28.0)(n=319)$ & NS \\
\hline \multirow[t]{6}{*}{ Cardiovascular risk factors } & Hypertension & $7 / 22(31.8 \%)$ & $169 / 380(44.5 \%)$ & NS \\
\hline & Diabetes & $6 / 22(27.3 \%)$ & $50 / 380(13.2 \%)$ & 0.063 \\
\hline & Hyperlipemia $^{a}$ & $0 / 16(0 \%)$ & $14 / 333(4.2 \%)$ & NS \\
\hline & Coronary heart disease & $10 / 22(45.5 \%)$ & $86 / 377(22.8 \%)$ & 0.016 \\
\hline & Cerebrovascular disease & $2 / 21(9.5 \%)$ & 18/363 (5.0\%) & NS \\
\hline & Left heart insufficiency & $8 / 22(36.4 \%)$ & $31 / 379(8.2 \%)$ & $<0.001$ \\
\hline \multirow[t]{5}{*}{ Other respiratory diseases } & Asthma & $1 / 22(4.5 \%)$ & $3 / 377(0.8 \%)$ & NS \\
\hline & Bronchiectasis & $5 / 22(22.7 \%)$ & $60 / 379(15.8 \%)$ & NS \\
\hline & Interstitial lung changes & $2 / 19(10.5 \%)$ & $26 / 341(7.6 \%)$ & NS \\
\hline & Lung cancer & $0 / 22(0 \%)$ & $8 / 379(2.1 \%)$ & NS \\
\hline & Ex-tuberculosis & $2 / 22(9.1 \%)$ & $94 / 379(24.8 \%)$ & NS \\
\hline \multirow[t]{6}{*}{ COPD-related treatment in stable period } & Regular LAMA & $6 / 24(25.0 \%)$ & $137 / 390(35.1 \%)$ & NS \\
\hline & Regular ICS/LABA & $5 / 24(20.8 \%)$ & 170/388 (43.8\%) & 0.027 \\
\hline & Regular ICS/LABA/LAMA & 2/24 (8.3\%) & $94 / 387(24.3 \%)$ & NS \\
\hline & Regular theophylline & $5 / 24(20.8 \%)$ & $97 / 384(25.3 \%)$ & NS \\
\hline & Oxygen therapy & 10/24 (41.7\%) & 167/388 (43.0\%) & NS \\
\hline & Noninvasive mechanical ventilation & $3 / 23(13.0 \%)$ & 40/372 (10.8\%) & NS \\
\hline \multirow[t]{2}{*}{ Pre-study exacerbations in 12 months } & Total numbers & $2(1-2.5)(n=17)$ & $2(1-3)(n=337)$ & NS \\
\hline & Hospitalization numbers & $2(1-2)(n=17)$ & $1(1-2)(n=335)$ & 0.025 \\
\hline
\end{tabular}

Data were shown as number (percentage), $\mathrm{n} / \mathrm{N}$ (percentage) or median (IQR). $P$-values between two group were calculated by Fisher's exact test, Chi-square test, or Mann-Whitney U test

CVEs cardiovascular events, $B M I$ body mass index, $F E V_{1}$ forced expiratory volume in one second, COPD chronic obstructive pulmonary disease, GOLD Global Initiative for Chronic Obstructive Lung Disease, mMRC modified Medical Research Council, CAT COPD Assessment test, ICS inhaled glucocorticoid, LABA long-acting beta agonist, LAMA long-acting muscarinic antagonist

${ }^{a}$ Hyperlipemia was defined as total cholesterol $>5.2 \mathrm{mmol} / \mathrm{L}$ in the AE period, for lack of lipid profile examination in the stable period

\section{Acute CVEs were associated with poor outcomes in AECOPD patients}

In comparison with non-CVEs group, increased death risk in hospital was observed in the acute CVEs group, with the constituent ratio of $13.3 \%$ versus $2.6 \%$ $(P=0.001, \mathrm{OR}=5.81,95 \% \mathrm{CI}=1.75-19.26)$. (Table 2$)$ Moreover, patients with acute CVEs had longer hospital stay and more frequent re-exacerbation of COPD within a 3 month period.
Risk factors of acute CVEs identified by univariate analysis As shown in Table 3, common respiratory symptoms such as cough, expectoration, hemoptysis, shortness of breath and chest pain, were not indicators of acute CVEs,. Additionally, fever, chill and cyanosis were not related to acute CVEs. Abnormal increase in heart rate and new or worsening edema of both lower limbs indicated subsequent cardiac deterioration. 
Table 2 Clinical outcomes between acute CVEs group and normal group

\begin{tabular}{|c|c|c|c|c|c|}
\hline Outcomes & $\begin{array}{l}\text { Acute CVEs group } \\
(n=30)\end{array}$ & No CVEs group $(n=466)$ & $P$ value & Odds ratio & $95 \% \mathrm{Cl}$ \\
\hline Hospital mortality & $4 / 30(13.3 \%)$ & $12 / 466(2.6 \%)$ & 0.001 & 5.821 & $1.75-19.30$ \\
\hline ICU admission & $2 / 30(6.7 \%)$ & $26 / 466(5.6 \%)$ & NS & & \\
\hline Hospital LOS (d) & $14(12-18)$ & $13(10-15)$ & 0.022 & & \\
\hline Re-AE at 1 month & $8 / 26(30.8 \%)$ & $64 / 443(14.5 \%)$ & 0.025 & 2.632 & $1.10-6.31$ \\
\hline Accumulative death at 1 month & $4 / 30(13.3 \%)$ & $15 / 455(3.3 \%)$ & 0.006 & 4.513 & $1.40-14.57$ \\
\hline Re-AE at 3 month & $14 / 26(53.8 \%)$ & $138 / 440(31.4 \%)$ & 0.018 & 2.553 & $1.15-5.67$ \\
\hline Accumulative death at 3 month & $6 / 30(20 \%)$ & $20 / 455(4.4 \%)$ & $<0.001$ & 5.438 & $1.99-14.79$ \\
\hline Re-AE at 6 month & $15 / 24(62.5 \%)$ & 195/435 (44.8\%) & NS & & \\
\hline Accumulative death at 6 month & $6 / 30(20 \%)$ & $25 / 455(5.5 \%)$ & 0.002 & 4.30 & $1.61-11.47$ \\
\hline
\end{tabular}

Data were shown as $\mathrm{n} / \mathrm{N}$ (percentage) or median (IQR). $P$-values between two group were calculated by Fisher's exact test, Chi-square test, or Mann-Whitney $\mathrm{U}$ test CVEs cardiovascular events, $C l$ confidence index, ICU intensive care unit, LOS length of stay, $A E$ acute exacerbation

Elevated neutrophils and C-reactive protein, suggesting aggravated inflammation, had a weak association with acute CVEs. Procalcitonin and erythrocyte sedimentation rate were excluded from the analysis, because they were not routinely tested for in patients with AECOPD. Indices of myocardial damage and heart failure, namely lactic dehydrogenase and $\mathrm{N}$-terminal proB-type natriuretic peptide (NT-proBNP), were significantly up-regulated in the acute CVEs group. As a promising variable in COPD management, neither absolute counts nor binary classification $(150 / \mu \mathrm{l})$ of eosinophils had any statistical association with acute CVEs. Additionally, patients in the acute CVEs groups had more complications in the $\mathrm{AE}$ period, including pneumothorax, pulmonary embolism and electrolyte disturbance. Whereas, pneumonia and respiratory failure were not associated with acute CVEs.

As indicated in Fig. 2, use of inhaled beta receptor agonists and muscarinic agonists in the AE period was not associated with an increased occurrence of acute CVEs but had slightly protective effects. Interestingly, use of inhaled glucocorticoid agents had a tendency to prevent acute CVEs $(P=0.066, \mathrm{OR}=0.49,95 \%$ $\mathrm{CI}=0.22-1.02)$, compared with aerosol inhalation of venous glucocorticoid agents $(P=0.22)$. Among 496 cases, 490 cases received antibiotics, of whom nearly $1 / 5$ received combined antibiotic therapy. Although use of fluoroquinolone was found to be risk factor for QTc prolongation in a previous study, [15] it was not statistically associated with acute CVEs in our cohort. In addition, 3 cases received macrolides and 6 cases received anti-fungal agents, and were thus not included into statistical analysis.

Preventive anticoagulation and nutrition support were predictors of acute CVEs, which might be attributed to poor baseline status of patients. (Fig. 2) Nine of 23 patients using digitalis had acute CVEs in the AE period, with 3 being treated for LVD and another 6 for controlling ventricular rate.

\section{Increased heart rate, electrolyte disturbance and use of diuretics were independent risk factors}

After removing 90 cases with missing data, 406 cases (20 CVEs and 386 non-CVEs) were included into the multivariate analysis. In Table 4 , a total of eight variables with $P<0.001$ in the univariate analysis were included into the binary logistic regression equation. Previous LVD, 20\% increase in heart rate (HR), electrolyte disturbance and diuretics use were independent predictors of acute CVEs in the AE period. Moreover, approximately $1 / 3$ of the patients receiving diuretics had electrolyte disturbance at admission.

\section{Discussion}

We demonstrated that the development of acute CVEs during AECOPD period was not only associated with increased hospital mortality but also with increased risks of short-term re-AE after discharge. Moreover, previous LVD, increased HR, electrolyte disturbance and diuretics use were identified as independent risk predictors of CVEs.

In line with our findings of increased HR and acute CVEs, other investigators also noted that increased resting HR was associated with a shortened life expectancy and increased cardiovascular mortality in COPD patients irrespective of the spirometric grading [21]. However, the relationship between electrolyte imbalance and CVEs remains to be confirmed. Our findings partly validated previous results of poor outcomes of hyperphosphatemia (only for male) [22] and hypocalcemia [23] in AECOPD patients. Whereas, no statistical difference in sodium, potassium and chlorides levels was observed between 
Table 3 Other cardiovascular risk factors in the univariate analysis

\begin{tabular}{|c|c|c|c|c|c|c|}
\hline Category & Variables & Acute CVEs group $(n=30)$ & No CVEs group $(n=466)$ & $P$ value & Odd ratio & $95 \% \mathrm{Cl}$ \\
\hline \multirow[t]{4}{*}{ Symptoms and signs } & Palpitation & $2 / 20(10.0 \%)$ & $9 / 388(2.3 \%)$ & 0.039 & 4.68 & $0.94-23.27$ \\
\hline & $20 \%$ increase in HR & $5 / 20(25.0 \%)$ & $11 / 386(2.8 \%)$ & $<0.001$ & 11.36 & $3.50-36.86$ \\
\hline & Both lower limb edema & $10 / 20(50.0 \%)$ & 70/389 (18.0\%) & $<0.001$ & 4.56 & $1.83-11.37$ \\
\hline & Disturbance of consciousness & $4 / 20(20.0 \%)$ & 19/387 (4.9\%) & 0.004 & 4.84 & $1.48-15.90$ \\
\hline \multirow[t]{22}{*}{ Laboratory tests } & Neutrophil (\%) & $80.85(73.18-86.05)$ & $75.50(67.55-83.50)$ & 0.035 & & \\
\hline & $\geq 80$ & $16 / 30(53.3 \%)$ & $165 / 466(35.4 \%)$ & 0.048 & 2.09 & $0.99-4.38$ \\
\hline & CRP $(\mathrm{mg} / \mathrm{L})(\mathrm{n}=478)$ & $33.4(12.45-68.55)$ & $19.2(4.95-61.1)$ & NS & & \\
\hline & $\geq 10$ & $24 / 29(82.8 \%)$ & $280 / 449(62.4 \%)$ & 0.028 & 2.90 & $1.09-7.74$ \\
\hline & Urea nitrogen (mmol/L) & $6.80(4.55-9.88)$ & $5.50(4.30-7.10)$ & 0.031 & & \\
\hline & $\geq 7.5$ & $14 / 30(46.7 \%)$ & $102 / 459(22.2 \%)$ & 0.002 & 3.06 & $1.45-6.49$ \\
\hline & $\operatorname{cTnT}(n g / m L)(n=333)$ & $0.02(0.01-0.03)$ & $0.01(0-0.02)$ & 0.054 & & \\
\hline & $>0.03$ & $6 / 28(21.4 \%)$ & $39 / 304(12.8 \%)$ & NS & & \\
\hline & $\mathrm{LDH}(\mathrm{U} / \mathrm{L})$ & $316(198-404)$ & $208(181-257)$ & 0.002 & & \\
\hline & $>245$ & $16 / 25$ (64.0\%) & $120 / 413(29.1 \%)$ & $<0.001$ & 4.34 & $1.87-10.10$ \\
\hline & $\begin{array}{l}\text { NT-proBNP } \\
(\mathrm{pg} / \mathrm{ml})(\mathrm{n}=218)\end{array}$ & $993(268-1875)$ & $296(139-1070)$ & 0.021 & & \\
\hline & $\geq 300$ & 13/17 (76.5\%) & 100/201 (49.8\%) & 0.043 & & \\
\hline & D-dimer (ug/L) & $0.77(0.43-1.21)$ & $0.52(0.27-1.04)$ & NS & & \\
\hline & $\geq 0.5$ & $16 / 25$ (64.0\%) & 235/448 (52.5\%) & NS & & \\
\hline & FBG (mmol/L) & $7.0(5.6-7.3)$ & $5.5(4.7-6.8)$ & 0.007 & & \\
\hline & $\geq 7$ & 9/27 (33.3\%) & 95/421 (22.6\%) & NS & & \\
\hline & Cholesterol (mmol/L) & $3.90(2.92-4.34)$ & $4.19(3.61-4.98)$ & 0.016 & & \\
\hline & LDL (mmol/L) & $2.20(1.58-2.67)$ & $2.62(2.11-3.11)$ & 0.013 & & \\
\hline & $\mathrm{PaO} 2(\mathrm{mmHg})$ & $80.50(64.25-108.25)$ & $78.5(65-100)$ & NS & & \\
\hline & $\leq 60$ & $4 / 28(14.3 \%)$ & $80 / 422(19.0 \%)$ & & & \\
\hline & $\mathrm{PaCO} 2(\mathrm{mmHg})$ & $51.0(39.0-66.0)$ & $47(41-58)$ & NS & & \\
\hline & $\geq 50$ & 15/27 (55.6\%) & $185 / 416(44.5 \%)$ & & & \\
\hline \multirow[t]{2}{*}{ CT manifestation } & Pleural effusion & 9/25 (36.6\%) & 75/389 (19.3\%) & 0.046 & 2.34 & $1.00-5.50$ \\
\hline & multiple lobes'lesion & 6/23 (26.1\%) & $94 / 390(24.1 \%)$ & NS & & \\
\hline \multirow[t]{3}{*}{ Complications } & Pneumothorax & 4/30 (13.3\%) & $1 / 466(0.2 \%)$ & $<0.001$ & 71.54 & $7.71-663.4$ \\
\hline & Pulmonary embolism & $2 / 30(6.7 \%)$ & $3 / 457(0.6 \%)$ & 0.03 & 10.81 & $1.73-67.38$ \\
\hline & Electrolyte disturbance & $11 / 30(36.7 \%)$ & $53 / 462(11.5 \%)$ & $<0.001$ & 4.47 & $2.02-9.90$ \\
\hline
\end{tabular}

Data were shown as $\mathrm{n} / \mathrm{N}$ (percentage) or median (IQR). $P$-values between two group were calculated by Fisher's exact test, Chi-square test, or Mann-Whitney $\mathrm{U}$ test CVEs cardiovascular events, $C l$ confidence index, HR heart rate, CRP C-reactive protein, ESR erythrocyte sedimentation rate, $C T n T$ cardiac muscle isoform of troponin T, LDH lactate dehydrogenase, NT-pro BNP N-terminal pro-brain natriuretic peptide, $F B G$ fasting blood glucose, $L D L$ low-density lipoprotein, $P a O_{2}$ partial pressure of oxide in artery, $\mathrm{PaCO}_{2}$ partial pressure of carbon dioxide in artery, $\mathrm{CT}$ computed tomography

acute CVEs and non-CVEs group in our cohort. Another study also reported no correlation between electrolyte imbalance and QTc prolongation in hospitalized patients with COPD [24]. As for diuretics use, a retrospective study reported that prescription of loop diuretics increased the risks of $\mathrm{AE}$ and death in the elderly patients with COPD [25]. In our cohort, we defined the diuretic usage as using loop diuretics and spironolactone, and found that diuretic usage was independently associated with acute CVEs. Contrarily, thiazide diuretics were recommended as the first-line antihypertensive agents for COPD patients, since it did not cause an increase in the numbers of $\mathrm{AE}$ [26]. Thus, mild diuretics and low-dosage might be more suitable for patients with AECOPD.

We speculate that cardiovascular risks of diuretics might result from electrolyte imbalance, hypovolemia or pre-existing heart failure. Moreover, increased HR is also one of the signs of hypovolemia. Two typical cases of acute CVEs in our cohort demonstrated that inappropriate usage of diuretics could result in electrolyte imbalance or hypovolemia. Patient A was a typical case, whose electrolyte disturbance led to worsening of his previous LVD. Before admission, he had edema of both lower extremities and took oral diuretics on his own. On 


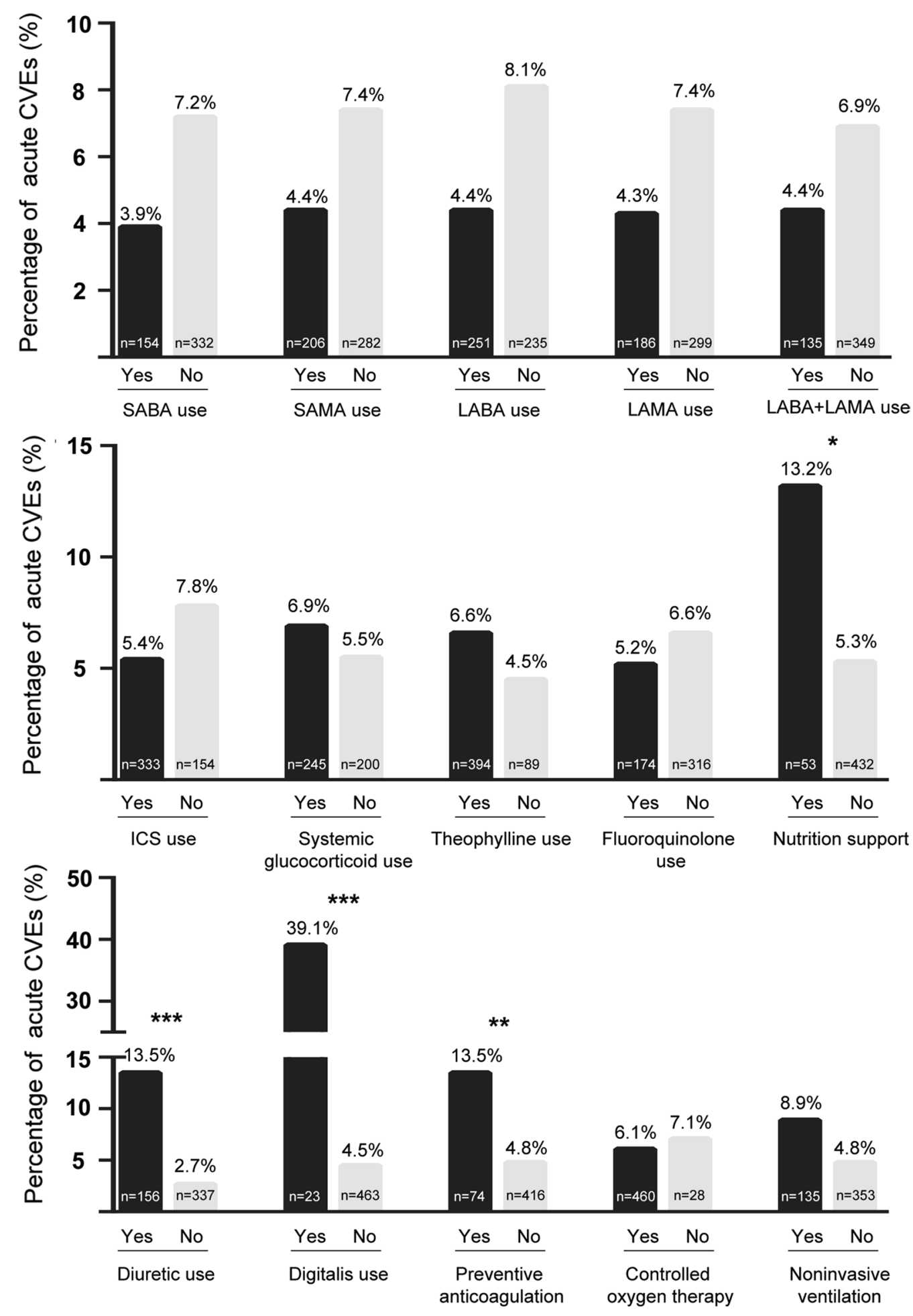

Fig. 2 Commonly-used medications and acute CVEs. Usage of SABA, SAMA, ICS here included either aerosol inhalation or specialized commercial agents. CVEs, cardiovascular events; SABA, short-acting beta agonist; SAMA, short-acting muscarinic antagonist; LABA, long-acting beta agonist; LAMA, long-acting muscarinic antagonist; ICS, inhaled glucocorticoid. ${ }^{*} P<0.05$; ${ }^{*} P<0.01$; ${ }^{* *} P<0.001$ 
Table 4 Predictors of acute CVEs in a multivariable logistic regression model

\begin{tabular}{|c|c|c|c|}
\hline Characteristic & Adjusted OR & $95 \% \mathrm{Cl}$ & Adjusted $P$-value \\
\hline $\begin{array}{l}\text { Previous left heart insuf- } \\
\text { ficiency }\end{array}$ & 5.06 & $1.66-15.36$ & 0.004 \\
\hline $20 \%$ increase in HR & 10.19 & $2.21-46.99$ & 0.003 \\
\hline Both lower limb edema & & & NS \\
\hline $\mathrm{LDH} \geq 245 \mathrm{U} / \mathrm{L}$ & & & NS \\
\hline Electrolyte disturbance & 4.24 & $1.40-12.77$ & 0.01 \\
\hline Pneumothorax & & & NS \\
\hline Diuretics use & 6.37 & $1.96-20.67$ & 0.002 \\
\hline Digitalis use & & & NS \\
\hline
\end{tabular}

CVEs cardiovascular events, $O R$ odds ratio, $\mathrm{Cl}$ confidence index, $H R$ heart rate, $L D H$ lactic dehydrogenase, NS non-significance

day 1 in hospitalization, he suddenly complained of dyspnea and orthopnea. Immediate laboratory tests showed he had hypokalemia $(2.6 \mathrm{mmol} / \mathrm{L})$, and hypochloridemia $(96 \mathrm{mmol} / \mathrm{L})$. Then, he was given potassium supplementation, digitalis, amrinone, intravenous and oral diuretics, along with noninvasive mechanical ventilation. On day 15 , he recovered and was discharged from hospital. Patient B was another typical example, whose hypovolemia led to the occurrence of arrhythmia. He had no edema of both lower extremities before admission. He was prescribed with intravenous diuretics on day 1-4 and converted into oral diuretics on day 5-7. On day 7 of hospitalization, he suddenly presented with a newly onset of atrial fibrillation. Immediate laboratory tests showed he had hypovolemia (erythrocyte counts $=5.88^{*} 10^{12}$ and hemoglobin $=184 \mathrm{~g} / \mathrm{L}$ ). He was given appropriate fluid infusion to expand blood volume, and discontinued diuretics. He was also given propafenone for cardioversion and oral amiodarone for maintenance. On day 9 , sinus rhythm was restored and patient was discharged from hospital on day 12. Thus, the above two cases suggested that electrolytes and blood volume should be closely monitored during the AE period, especially in the patients receiving diuretics. As a golden standard of hemodynamic assessment, right heart catheterization is, however, limitedly carried out in patients with AECOPD due to its invasiveness and patients' poor status. Hence, new echocardiographic parameters are recommended in the clinical setting, including tricuspid annular plane systolic excursion (TAPSE) and systolic $S^{\prime}$ velocity of the tricuspid annulus. [27]

Similar to our results of increased NT-proBNP in acute CVEs group, NT-proBNP levels [28] were previously found to be strong indicators of death in patients with AECOPD. Likewise, Smith GL reported that increased urea nitrogen was associated with cardiovascular mortality in the elderly. [29] Although Smith GL showed the association of increased creatinine level with myocardial infarction $(>88.4 \mathrm{mmol} / \mathrm{L})$ and heart failure (>97.2 mmol/L) [29], we did not confirm this association in our study. Theophylline, fluoroquinolone and inhaled bronchodilators in AE period, which were previously regarded as cardiovascular risk factors [14-16], were not statistically associated with acute CVEs in our cohort.

Since nearly half of AEs are caused by lower respiratory bacterial infection [30], we tried to gain insights from some studies of Community-Acquired Pneumonia (CAP) and associated cardiac complications. Similar to our study, two observational studies reported that incident CVEs was a strong negative indicator of 30-day survival of patients with CAP [31,32]. In the comprehensive analysis of three CAP studies $(25-40 \%$ of subjects with chronic respiratory diseases), several risk factors for acute CVEs including age, preexisting coronary heart disease, diabetes, congestive heart failure, pleural effusion, increased pulse, urea nitrogen, and blood glucose had been identified [31-33]. These finding are consistent with our results.

Some limitations should be noted before interpreting this study. As a nested case-control study, absolute causal relationship cannot be confirmed, and incidence and mortality of acute CVEs in patients with AECOPD cannot be calculated. Second, due to a limited number of acute CVEs and statistical efficacy, some risk factors might have been missed. We plan to further validate our results in a large-scale and multicenter cohort with more outcomes of CVEs. Third, some baseline information in the stable period was missing, and use of cardioprotective medications e.g. anti-platelet agents and statins was not fully recorded,, which might result in biases [14, 34]. Fourth, baseline comorbidities were reported by patients themselves and not validated by detailed laboratory tests, which might have led to recall bias. Fifth, we did not take some useful scales of cardiovascular risk assessment into consideration [35].

\section{Conclusion}

Cardiac complications in AE period were significantly associated with poor outcomes in patients with COPD. Patients with previous history of LVD and 20\% increase in HR were susceptible to cardiac complications and needed close monitoring. Furthermore, diuretics use in $\mathrm{AE}$ period might be associated with underlying cardiovascular risks, and electrolytes and blood volume should be carefully assessed.

\section{Abbreviations}

COPD: Chronic obstructive pulmonary disease; CVEs: Cardiovascular events; AE: Acute exacerbation; ACS: Acute coronary syndrome; LVD: Left ventricular 
disfunction; HR: Heart rate; CVD: Cardiovascular disease; mMRC: Modified Medical Research Council; CAT: COPD assessment test; GOLD: Global Strategy for Prevention, Diagnosis and Management of COPD; re-AE: Recurrent acute exacerbation; NT-proBNP: N-terminal proB-type natriuretic peptide; SpO2: Oxygen saturation; cTnl: Cardiac troponin l; RHF: Right heart failure; TAPSE: Tricuspid annular plane systolic excursion; CAP: Community-acquired pneumonia.

\section{Acknowledgements}

The authors sincerely acknowledged Dr Shi Xiao and Dr Bashwin-Hanssa Summah for meticulously scrutinizing this article for English writing.

\section{Authors' contributions}

Study design: WPH, TL, SQL, JZ; Data Collection: TL, FYZ, JQH, YHZ, JLH; Statistical analysis: WPH, TL; Manuscript writing: WPH, TL; Critical manuscript revision: WPH, JZ. All authors read and approved the final manuscript.

\section{Funding}

This study was funded by the National Key Research and Development Program of China (No. 2018YFC1313600) in the aspect of data collection, the National Natural Science Foundation of China (No. 81970035) in the aspect of data analysis, and Shanghai Municipal Key Clinical Specialty Program (shslczdzk02201) in the aspect of patient recruitment.

\section{Availability of data and materials}

The datasets used and/or analyzed during the current study available from the corresponding author on reasonable request.

\section{Ethics approval and consent to participate}

The establishment of this prospective COPD cohort was approved by Institutional Ethics Committee of Shanghai Zhongshan Hospital. (No. B2015-119R) All procedures were in line with the ethical standards of the institutional committee and with the 1964 Helsinki Declaration. Informed written consent of clinical information collection and follow up was acquired from each patient at admission.

\section{Consent to publication}

The statements of consent to publish from two patients in the Discussion section were acquired.

\section{Competing interests}

The authors declare that they have no competing interests.

\section{Author details}

${ }^{1}$ Department of Pulmonary and Critical Care Medicine, Zhongshan Hospital, Shanghai Medical College, Fudan University, Shanghai 200032, China.

${ }^{2}$ Department of Respiratory Medicine, Tibet Autonomous Region People's Hospital, Tibet, China. ${ }^{3}$ Department of Respiratory Medicine, Putuo District People's Hospital, Shanghai, China.

Received: 21 August 2020 Accepted: 30 November 2020 Published online: 10 December 2020

\section{References}

1. Celli BR, Wedzicha JA. Update on clinical aspects of chronic obstructive pulmonary disease. N Engl J Med. 2019;381(13):1257-66.

2. 2019 Global Strategy for Prevention, Diagnosis and Management of COPD (2019 report). Available at https://goldcopd.org/gold-reports/.

3. Huiart L, Ernst P, Suissa S. Cardiovascular morbidity and mortality in COPD. Chest. 2005;128(4):2640-6.

4. Sin DD, Anthonisen NR, Soriano JB, Agusti AG. Mortality in COPD: Role of comorbidities. Eur Respir J. 2006;28(6):1245-57.

5. McGarvey LP, John M, Anderson JA, Zvarich M, Wise RA, Committee TCE. Ascertainment of cause-specific mortality in COPD: operations of the TORCH Clinical Endpoint Committee. Thorax. 2007;62(5):411-5.

6. Sibila O, Mortensen EM, Anzueto A, Laserna E, Restrepo MI. Prior cardiovascular disease increases long-term mortality in COPD patients with pneumonia. Eur Respir J. 2014;43(1):36-42.
7. Mullerova H, Agusti A, Erqou S, Mapel DW. Cardiovascular comorbidity in COPD: systematic literature review. Chest. 2013;144(4):1163-78.

8. Smith MC, Wrobel JP. Epidemiology and clinical impact of major comorbidities in patients with COPD. Int J Chron Obstruct Pulmon Dis. 2014;9:871-88.

9. Rothnie KJ, Yan R, Smeeth L, Quint JK. Risk of myocardial infarction (MI) and death following $\mathrm{MI}$ in people with chronic obstructive pulmonary disease (COPD): a systematic review and meta-analysis. BMJ Open. 2015;5(9):e007824.

10. Lahousse L, Niemeijer MN, van den Berg ME, Rijnbeek PR, Joos GF, Hofman A, Franco OH, Deckers JW, Eijgelsheim M, Stricker BH, et al. Chronic obstructive pulmonary disease and sudden cardiac death: the Rotterdam study. Eur Heart J. 2015;36(27):1754-61.

11. Carter P, Lagan J, Fortune C, Bhatt DL, Vestbo J, Niven R, Chaudhuri N, Schelbert EB, Potluri R, Miller CA. Association of cardiovascular disease with respiratory disease. J Am Coll Cardiol. 2019;73(17):2166-77.

12. Wedzicha JA, Seemungal TA. COPD exacerbations: defining their cause and prevention. Lancet. 2007;370(9589):786-96.

13. Kunisaki KM, Dransfield MT, Anderson JA, Brook RD, Calverley PMA, Celli BR, Crim C, Hartley BF, Martinez FJ, Newby DE, et al. Exacerbations of chronic obstructive pulmonary disease and cardiac events: a post hoc cohort analysis from the SUMMIT Randomized Clinical Trial. Am J Respir Crit Care Med. 2018;198(1):51-7.

14. Rabe KF, Hurst JR, Suissa S: Cardiovascular disease and COPD: dangerous liaisons? Eur Respir Rev 2018; 27(149).

15. Gorelik E, Masarwa R, Perlman A, Rotshild V, Abbasi M, Muszkat M, Matok I. Fluoroquinolones and cardiovascular risk: a systematic review, metaanalysis and network meta-analysis. Drug Saf. 2019;42(4):529-38.

16. Wang MT, Liou JT, Lin CW, Tsai CL, Wang YH, Hsu YJ, Lai JH. Association of cardiovascular risk with inhaled long-acting bronchodilators in patients with chronic obstructive pulmonary disease: a nested case-control study. JAMA Intern Med. 2018;178(2):229-38.

17. Suissa S, Dell'Aniello S, Ernst P. Concurrent use of long-acting bronchodilators in COPD and the risk of adverse cardiovascular events. Eur Respir J. 2017; 49(5).

18. Hohlfeld JM, Vogel-Claussen J, Biller H, Berliner D, Berschneider K, Tillmann HC, Hiltl S, Bauersachs J, Welte T. Effect of lung deflation with indacaterol plus glycopyrronium on ventricular filling in patients with hyperinflation and COPD (CLAIM): a double-blind, randomised, crossover, placebo-controlled, single-centre trial. Lancet Respir Med. 2018;6(5):368-78.

19. Mahler DA, Harver A. A factor analysis of dyspnea ratings, respiratory muscle strength, and lung function in patients with chronic obstructive pulmonary disease. Am Rev Respir Dis. 1992;145(2 Pt 1):467-70.

20. Jones PW, Harding G, Berry P, Wiklund I, Chen WH, Kline Leidy N. Development and first validation of the COPD Assessment Test. Eur Respir J. 2009;34(3):648-54.

21. Jensen MT, Marott JL, Lange P, Vestbo J, Schnohr P, Nielsen OW, Jensen $J S$, Jensen GB. Resting heart rate is a predictor of mortality in COPD. Eur Respir J. 2013;42(2):341-9.

22. Campos-Obando N, Lahousse L, Brusselle G, Stricker BH, Hofman A, Franco $\mathrm{OH}$, Uitterlinden AG, Zillikens MC. Serum phosphate levels are related to all-cause, cardiovascular and COPD mortality in men. Eur J Epidemiol. 2018;33(9):859-71.

23. Qin J, Deng X, Wei A, Qin Y, Wu Y, Liao L, Lin F. Correlation between hypocalcemia and acute exacerbation of chronic obstructive pulmonary disease in the elderly. Postgrad Med. 2019;131(5):319-23.

24. Zilberman-Itskovich S, Rahamim E, Tsiporin-Havatinsky F, Ziv-Baran T, Golik A, Zaidenstein R. Long QT and death in hospitalized patients with acute exacerbation of chronic obstructive pulmonary disease is not related to electrolyte disorders. Int J Chron Obstruct Pulmon Dis. 2019;14:1053-61.

25. Vozoris NT, Wang X, Austin PC, O'Donnell DE, Aaron SD, To TM, Gershon AS. Incident diuretic drug use and adverse respiratory events among older adults with chronic obstructive pulmonary disease. Br J Clin Pharmacol. 2018;84(3):579-89.

26. Finks SW, Rumbak MJ, Self TH. Treating hypertension in chronic obstructive pulmonary disease. N Engl J Med. 2020;382(4):353-63.

27. Lang RM, Badano LP, Mor-Avi V, Afilalo J, Armstrong A, Ernande L, Flachskampf FA, Foster E, Goldstein SA, Kuznetsova T, et al. Recommendations for cardiac chamber quantification by echocardiography in adults: 
an update from the American Society of Echocardiography and the European Association of Cardiovascular Imaging. J Am Soc Echocardiogr. 2015;28(1):1-39.

28. Hoiseth AD, Omland T, Hagve TA, Brekke PH, Soyseth V. NT-proBNP independently predicts long term mortality after acute exacerbation of COPD - a prospective cohort study. Respir Res. 2012;13:97.

29. Smith GL, Shlipak MG, Havranek EP, Foody JM, Masoudi FA, Rathore SS, Krumholz HM. Serum urea nitrogen, creatinine, and estimators of renal function: mortality in older patients with cardiovascular disease. Arch Intern Med. 2006;166(10):1134-42.

30. Sethi S, Murphy TF. Infection in the pathogenesis and course of chronic obstructive pulmonary disease. N Engl J Med. 2008;359(22):2355-65.

31. Corrales-Medina VF, Musher DM, Wells GA, Chirinos JA, Chen L, Fine MJ. Cardiac complications in patients with community-acquired pneumonia: incidence, timing, risk factors, and association with short-term mortality. Circulation. 2012;125(6):773-81.

32. Violi F, Cangemi R, Falcone M, Taliani G, Pieralli F, Vannucchi V, Nozzoli C, Venditti M, Chirinos JA, Corrales-Medina VF, et al. Cardiovascular complications and short-term mortality risk in community-acquired pneumonia. Clin Infect Dis. 2017;64(11):1486-93.

33. Corrales-Medina VF, Taljaard M, Fine MJ, Dwivedi G, Perry JJ, Musher DM, Chirinos JA. Risk stratification for cardiac complications in patients hospitalized for community-acquired pneumonia. Mayo Clin Proc. 2014;89(1):60-8.

34. Feldman C, Anderson R. Community-acquired pneumonia: pathogenesis of acute cardiac events and potential adjunctive therapies. Chest. 2015:148(2):523-32.

35. Zagaceta J, Bastarrika G, Zulueta JJ, Colina I, Alcaide AB, Campo A, Divo M, Casanova C, Marin JM, Pinto-Plata VM, et al. Prospective comparison of non-invasive risk markers of major cardiovascular events in COPD patients. Respir Res. 2017;18(1):175.

\section{Publisher's Note}

Springer Nature remains neutral with regard to jurisdictional claims in published maps and institutional affiliations.
Ready to submit your research? Choose BMC and benefit from:

- fast, convenient online submission

- thorough peer review by experienced researchers in your field

- rapid publication on acceptance

- support for research data, including large and complex data types

- gold Open Access which fosters wider collaboration and increased citations

- maximum visibility for your research: over 100M website views per year

At BMC, research is always in progress.

Learn more biomedcentral.com/submissions 